\title{
TRES PLANTAS POCO CONOCIDAS DE LA FLORA MEXICANA
}

\author{
Por el Prof. Eizi MATUDA.
}

Carludovica chiapensis Matuda. Bull. Torr. Bot. Club. 76. 3. 210 212. Mayo de 1949.

Es una planta trepadora, parecida a las Aràceas por sus tallos, raices y hojas.

El género fué establecido por Ruiz y Pavón en honor de Carlos IV y de la reina Luisa. En Costa Rica se encuentra la Carludovica utilis, y en el norte de Sud América la Carludovica palmata, con cuyas hojas se fabrican los sombreros llamados de Panamá. En nuestro territorio existe la Carludovica gracilis, en Jocotepec, Oax.

La Carludovica chiapensis se encuentra en la zona de Tapachula, Chis., y se conoce popularmente con el nombre de tepejilote. La inflorescencia tierna es comestible; su sabor es amargo, pero se atenúa hirviéndola dos o tres veces.

Dracontium soconuscum Matuda. The Midland Nat. Marzo de 1948.

Este género es endémico en Panamá y Costa Rica, representado en este último país por el Dracontium giganteum, de inflorescencia enorme. Tiene alguna semejanza con el Amorphophallus de Japón y China, pero su tubérculo no produce el pegamento que llaman mannan, como el del Amorphophallus. La inflorescencia brota directamente del tubérculo y dura más de un mes. Se encuentra en el Distrito de Soconusco, Chis.

Mitrastemon matudai Yam.

Fué descrito hace 10 años en el Japón y era solamente conocido

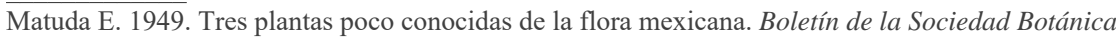
de México 9: 1-4. 


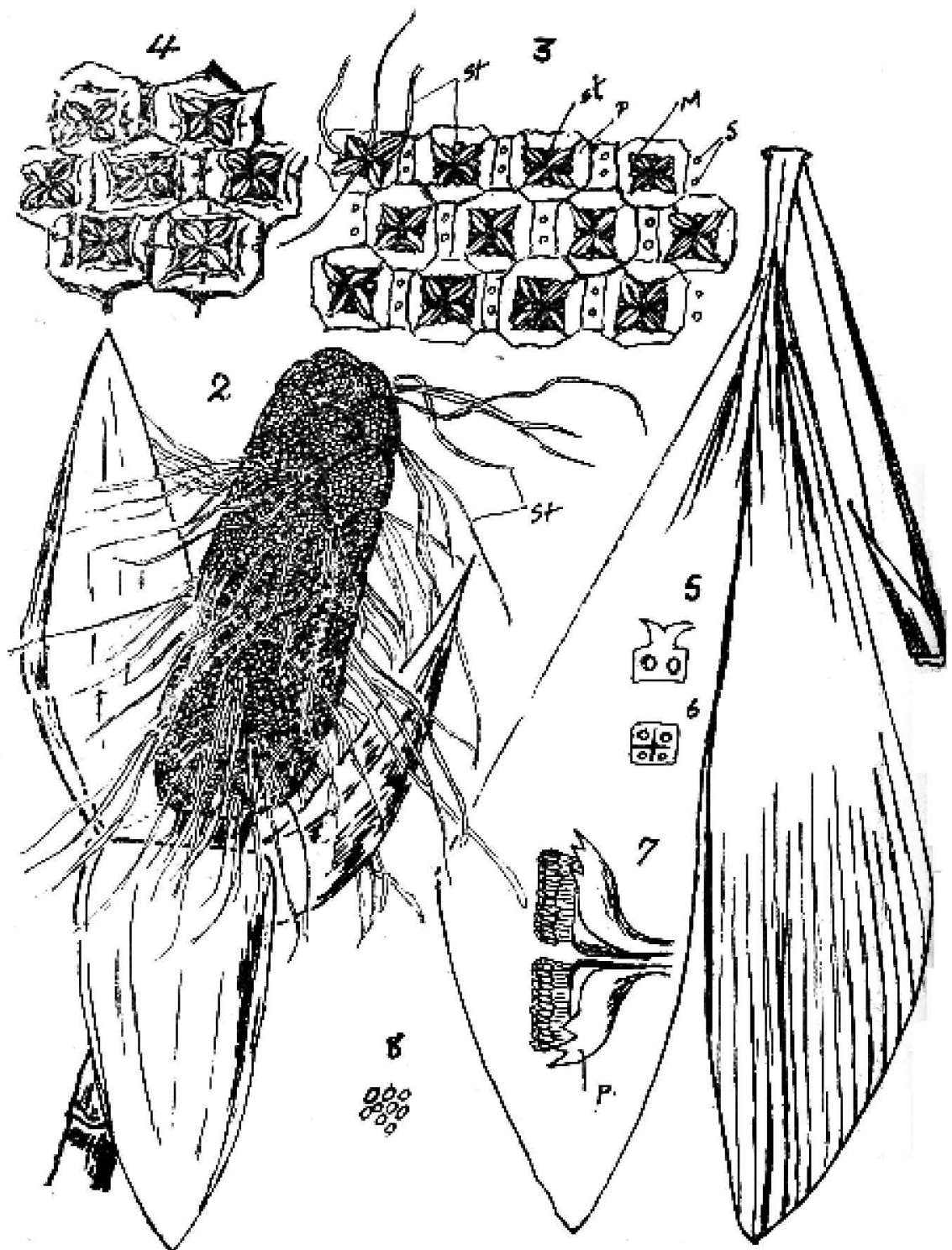

Fig. 1. Cortudovica chiapenzis Matuda, 1, hoja; a. espata y espadice. st, estaminoides; 3 , pistilo despuŕs de remover la flor masculina. st, estaminoides; periantio; 5 , luger de la flor nabeliana. 4. Pistilo mús thotrollado, poco anfes do la madurez. 5. sección vertical dal pistilo. 6, socich transversul. 7 , flor wasculina. $P$, periantio. 


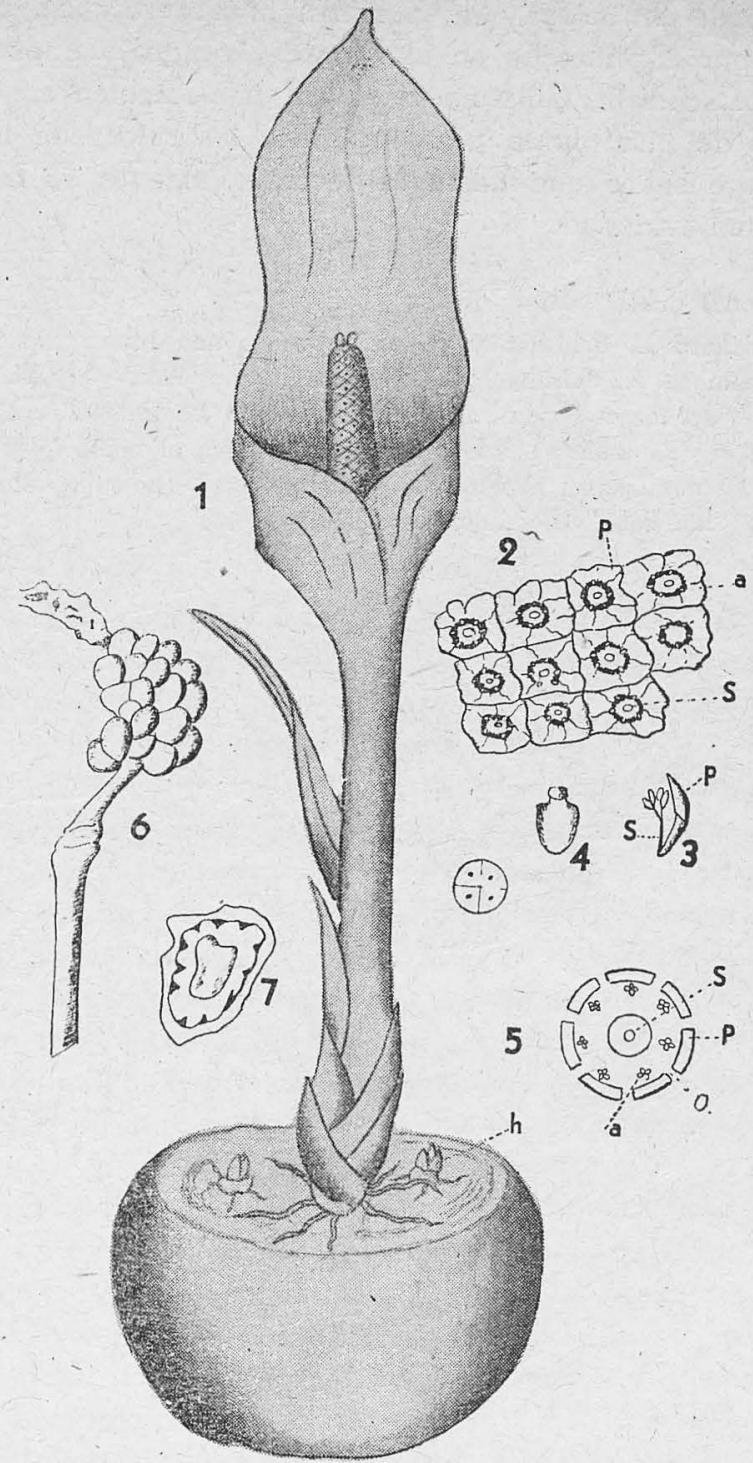

Fig. 2. Dracontium soccnuscum Matuda- - 1, flor colocada sobre la raiz tuberosa. $h$, retoño. 2, superficie del espadice; a, anteras; $P$, periantio; $S$, estigmał 3, periantio con el estambre. $\mathrm{P}$, periantio; $\mathrm{S}$, estambre. 4, ovario con el estigma y su sección transversal. 5, sistema floral. a, anteras; $\mathrm{P}$, periantio; $\mathrm{S}$, estigma; O, ovario. 6 , frutos. 7 , sección vertical de la semilla. 
de ese pais, de Formosa y de Sumatra holandesa. En México fué encontrado por el subscrito en el Monte Ovando, a unos $24 \mathrm{Km}$. al noroeste de Escuintla, Chis. en 1934. Existe también en Guatemala.

Se trata de una planta parásita sobre las raíces de los encinos. Es interesante saber que hasta la fecha solamente se conocen dos especies y una variedad.

Nota adicional del Dr. B. P. Reko.

El Dr. Richard E. Schultes y yo encontramos una nueva especie de Carludovica (C. labela R. E. Schultes) entre Santa María Yahuivé y Santiago Yaveo en la Chinantla en mayo 15 de 1939. Bot. Museum Leaflets, Harvard Univ. vol. 9. Núm. 9. 194.1. También es planta trepadora y lleva el nombre "rabo de bobo", traducción de su nombre en zapoteco"laga xbana bela" (hoja de cola de pescado) o simplemente "laa bela" (haja de pescado).

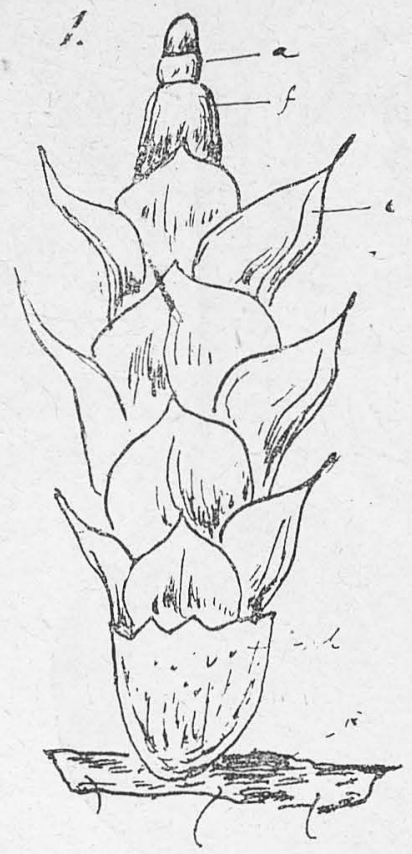

Fig. 3. Mitrastemon.- 1, Mitrastemon Matudai Yam. a, anteras unidas; f, filamentos unidos; a. y f. forman un capuchón o mitra que dae después de madurar el polen, apareciendo entonces la flor femenina en la extremidad del tallo. c, escamas en lugar de hojas; $R$, raíz del patrón; b, parte basal del periantio. 2, Esquema del tipo del género. 